\title{
Summer upwelling at the Boknis Eck time-series station (1982 to 2012) - a combined glider and wind data analysis
}

\author{
J. Karstensen ${ }^{1}$, T. Liblik ${ }^{1,2}$, J. Fischer ${ }^{1}$, K. Bumke ${ }^{1}$, and G. Krahmann ${ }^{1}$ \\ ${ }^{1}$ GEOMAR Helmholtz Centre for Ocean Research Kiel, Düsternbrooker Weg 20, 24105 Kiel, Germany \\ ${ }^{2}$ Marine Systems Institute at Tallinn University of Technology, MSI, Akadeemia tee 15a, 12618 Tallinn, Estonia \\ Correspondence to: J. Karstensen (jkarstensen@geomar.de)
}

Received: 25 January 2014 - Published in Biogeosciences Discuss.: 18 February 2014

Revised: 4 June 2014 - Accepted: 5 June 2014 - Published: 4 July 2014

\begin{abstract}
Two consecutive summer upwelling events, each lasting for less than $24 \mathrm{~h}$, were surveyed in high temporal and vertical resolution close to the Boknis Eck time-series station (BE) in the western Belt Sea (Baltic Sea) in summer 2010 with an autonomous glider. Driven only by moderate offshore winds both events resulted in more than $5 \mathrm{~K}$ cooling of surface waters, while only for the second event were significant irreversible changes in the vertical stratification observed. Generalizing the glider survey observations with hourly wind data from nearby meteorological stations, it is found that upwelling in the BE area occurs for wind directions between 190 to $260^{\circ}$ and wind speed exceeding $4 \mathrm{~m} \mathrm{~s}^{-1}$. Based on these thresholds the wind-induced summer (June to September) upwelling conditions in the BE area for the period 1982 to 2012 are reconstructed. On average about 18 days of upwelling favourable wind conditions are found for the four summer months, with significant interannual variability ranging from 7.7 days (2006) to more than 28 days (1985). By aligning upwelling favourable wind conditions with the monthly BE surveys it is found that extreme anomalies in BE surveys follow extended periods of upwelling favourable winds.
\end{abstract}

\section{Introduction}

On seasonal timescales the strongest stratification in the marine environment is found in summer, when warm surface waters overlay colder deeper water masses. This intense stratification minimizes the vertical fluxes and has for example a strong impact on biogeochemical processes in the near-surface layer (Lips et al., 2009; Lass et al., 2010; Bed- norz et al., 2013). Different processes can enhance vertical fluxes and in turn add nutrients (and other substances) from below to the surface (see Lehmann and Myrberg, 2008, and references within for a review for the Baltic), while the key forcing is coastal parallel to offshore wind (Yoshida, 1955; Gill and Clarke, 1974). Since the Baltic Sea is an almost enclosed sea, any wind direction will generate upwelling at some shore. Beside the local upwelling response to the wind forcing the upwelling signal may propagate as a coastal Kelvin wave along the coast (Gill and Clarke, 1974; Fennel et al., 2010). At the sea surface, summer upwelling is rather easy to detect as a cold anomaly (Lehmann and Myrberg, 2008; Lehmann et al., 2012). However, the impact of the upwelling on a reorganization of the interior stratification is more difficult to estimate and it has been shown that in particular the intensity of the wind forcing and its temporal evolution play a major role (Myrberg et al., 2010).

Here we investigate observations of summer upwelling events at the location of the Boknis Eck time-series station (BE), located in the western Belt Sea (Fig. 1). The Belt Sea is the transition zone between the Baltic Sea and the North Sea. It occupies a surface area of about $17800 \mathrm{~km}^{2}$ and is rather shallow with a mean depth of $15 \mathrm{~m}$ (Leppäranta and Myrberg, 2009). The vertical stratification in the Belt Sea is in general determined by the seasonal stratification imprinted by surface buoyancy and momentum fluxes. The deep layers of the Belt Sea are mainly influenced by salty and relatively warm and dense water supplied by the North Sea inflow (e.g. Jakobsen et al., 2010). Although specific wind/sea level situations support extensive inflow events of North Sea water (e.g. Gustafsson and Omstedt, 2009), limited inflow always exists through the estuarine circulation driven by the 
outflowing low salinity water in the upper layer. Sluggish ventilation paired with strong stratification in summer drives in many parts of the Belt Sea a depletion of oxygen in the bottom layers. However, in winter overturning of near-surface waters typically re-ventilates the deep layer waters.

The BE is a time-series site that been sampled by ship visits approximately once a month since 1957 (Lennartz et al., 2014) and a variety of parameters with relevance for multiple disciplines (physical, chemical and biological) are routinely measured (see e.g. Schweiger et al., 2007; Bange et al., 2010; Dale et al., 2011; Bange et al., 2011; Bertics et al., 2013; Dähnke and Thamdrup, 2013). Variability from seasonal to long term have been described for a number of parameters sampled at BE (e.g. Lennartz et al., 2014; Hoppe et al., 2013) while episodic, event-type variability has not systematically being addressed. Here we investigate one prominent process that triggers drastic changes in the interior parameter fields, namely summer upwelling events.

Given the episodic nature of upwelling and its spatial variability, high-resolution sampling in time/space is of advantage to investigate processes in shallow seas. Scanfish-type systems, which are operated from moving ships, are rather well established. Autonomously operating systems, which require only limited human intervention and can be operated over extended periods of time, are rare. Recently, moored vertical profiling systems have been demonstrated to be a useful new tool for high-resolution sampling (Liblik and Lips, 2012).

Another emerging system for autonomous high-resolution sampling, and which was also used for this study, is an underwater glider. Gliders are autonomous vehicles that utilize vehicle buoyancy changes for vertical and horizontal movement. They are remotely controlled via satellite telephone communication. Data are accessible in near-real time, the sensor payload is flexible, and they can be optimized for surveying shallow depth waters. Although gliders have been used in many surveys in the open ocean as well as in coastal areas (e.g. Ruiz et al., 2009; Ramp et al., 2009) to our knowledge no application to the Baltic Sea has been reported so far.

This paper is structured as follows. The next section provides an overview of the data that have been used for the analysis (glider, satellite, BE and meteorological station data). The glider data sections of physical and biogeochemical variables are described in the following section and two upwelling events, that occurred during the survey, are analysed in more detail. Based on concurrent meteorological observations, upwelling favourable wind situations are identified. Utilizing wind data for the period 1982 to 2012 the summer upwelling occurrence in the BE region is investigated. In the following section the approximately monthly BE ship surveys are connected with upwelling-favourable wind situations derived from the wind time series. Finally, a connection between anomalies of selected variables that appear in the BE time series and the wind-induced upwelling is discussed.

\section{Data and methods}

\subsection{Glider survey}

A high-resolution glider survey was carried out between 9 July 2010 and 16 July 2010, about $500 \mathrm{~m}$ north of the nominal BE position $\left(54^{\circ} 31.77^{\prime} \mathrm{N}, 010^{\circ} 02.36^{\prime} \mathrm{E}\right)$. The glider was commanded to operate in a "virtual mooring mode", defined by two waypoints separated by about $750 \mathrm{~m}$ and located at the $20 \mathrm{~m}$ isobath (Fig. 1). Occasionally the glider left the virtual survey line due to short-term current events and drifted into water of different depth (up to $25 \mathrm{~m}$ toward the southeast and less than $10 \mathrm{~m}$ towards the northwest). The deployment and recovery of the glider were conducted from the RB Polarfuchs. The deployment was prepared by utilizing BE timeseries data suggesting that the glider should be ballasted to be neutrally buoyant for a density of $1011 \mathrm{~kg} \mathrm{~m}^{-3}$ and that a vertical density range of $8 \mathrm{~kg} \mathrm{~m}^{-3}$ was expected. The survey area is marked as a "restricted area" in the navigational charts and as such no ship traffic was expected during the operation.

The glider was a shallow depth (configured for $30 \mathrm{~m}$ water depth) SLOCUM G1 electric glider. The scientific payload included a SeaBird SBE41 "temperature, conductivity, pressure" probe, a turbidity/chlorophyll a (fluorescence) WetLabs ECO FLNTU Puck, and an AADI oxygen optode 3830. The scientific data were recorded with a sample rate of $1 \mathrm{~Hz}$ (oxygen with $0.5 \mathrm{~Hz}$ ) and approximately 700000 (oxygen 350000 ) data points of each variable were collected during the survey. On three occasions the glider ventured into shallow waters where it stranded at the sea floor. It remained there until a time-out $(4 \mathrm{~h})$ was triggered and the glider's autonomous system decided to change the buoyancy to let the vehicle ascend to the sea surface again.

The derivation of the salinities generally followed the procedure described by Garau et al. (2011). They showed that applying a glider-speed-dependent delay to the temperature allowed for the calculation of optimal, i.e. spike free, salinities. Optimal results were, for the average glider speed of $0.52 \mathrm{~m} \mathrm{~s}^{-1}(2 \mathrm{kn})$, achieved with a correction amplitude $\alpha$ of 0.14 and a delay timescale $\tau$ of $9.7 \mathrm{~s}$. The other sensors (turbidity, fluorescence, oxygen) were not corrected and the data presented here are based on the original factory calibrations. The data are internally recorded as a time series along the flight path, while for the analysis the data were interpolated onto a regular depth grid of $0.5 \mathrm{~m}$ vertical resolution. As such, the originally slanted profiles were considered vertical profiles. Altogether, 1254 gridded downcast profiles were used in the analysis (approximately one profile every 15 min). Measurements in the upper two metres are sparse due to internal vehicle control mechanisms. A reduced data set was transmitted via satellite approximately once an hour and, along with the data transmission, a GPS fix was acquired that was used by the vehicle to estimate a depth-integrated current through a dead reckoning algorithm. 


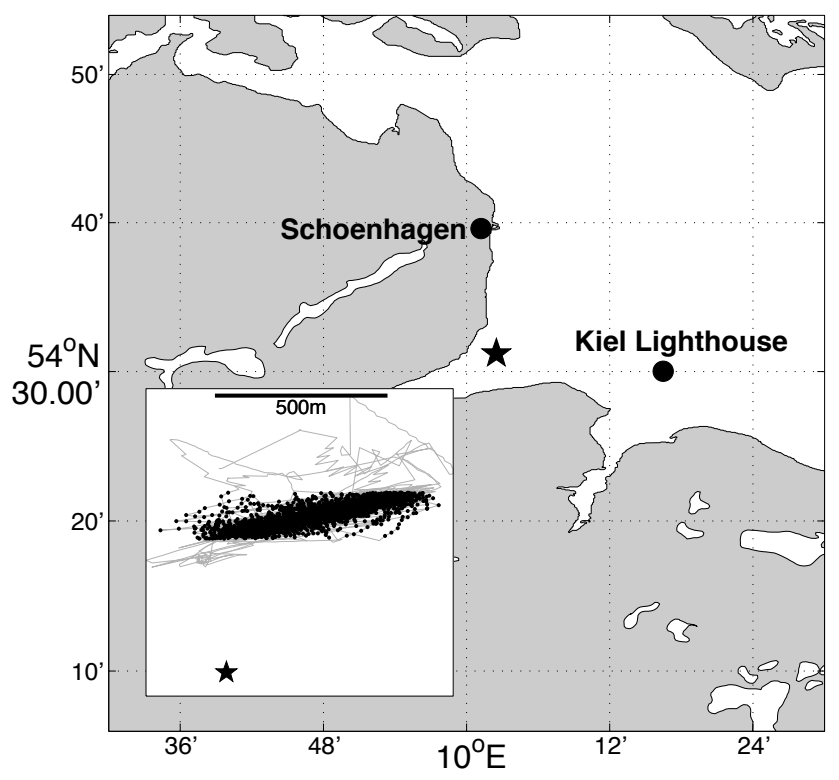

Figure 1. Overview map with Boknis Eck time-series station (black star) and the meteorological station Schönhagen and Kiel lighthouse. All glider tracks (grey lines) and the positions of glider observations used in this study (black dots) are shown in the inlay.

\subsection{Boknis Eck time series}

The $\mathrm{BE}$ is located approximately $1 \mathrm{~km}$ from the coast at the nominal position $54^{\circ} 31.77^{\prime} \mathrm{N}, 010^{\circ} 02.36^{\prime} \mathrm{E}$ in $28 \mathrm{~m}$ deep water. It is a ship survey-based time series with approximately monthly resolution, and was first surveyed in April 1957. Details on data collection and parameters have been described elsewhere (Bange et al., 2010; Dale et al., 2011; Bertics et al., 2013; Hoppe et al., 2013; Lennartz et al., 2014). Here we will use bottle data acquired at standard depth $(1,5$, $10,15,20,26 / 25 \mathrm{~m}$ ). We focus on the summer months (June to September) when a significant stratification is present at the location. Our primary goal is to identify the potential impact of upwelling on individual BE surveys and as such our focus is on parameters where we expect a strong impact of the upwelling to be visible. Moreover, the parameters should be accessible from BE and the glider sensor payload namely, we look at temperature, salinity, oxygen, and chlorophyll $a$ fluorescence.

\subsection{Meteorological data}

Observational data from two meteorological stations are used - Schönhagen and Kiel lighthouse (Fig. 1). Schönhagen is a certified weather station of the National Meteorological Service (DWD, id 5930) located approximately $12 \mathrm{~km}$ north of the BE site (Fig. 1) and close to the shore. Wind observations are acquired at $10 \mathrm{~m}$ height and started on 1 August 1981. Data before September 2007 were acquired at a location about $2.1 \mathrm{~km}$ further to the north of the current station.
A somewhat shorter data set, routinely available since 1 January 1988, stems from the Kiel lighthouse station. The lighthouse is located on a platform erected approximately $7 \mathrm{~km}$ from the nearest shore, at the opening of the Kiel Fjord. Until 1992 the sensors were mounted on a mast a few $10 \mathrm{~m}$ away from the lighthouse and later mounted directly on to the lighthouse tower at a height of $35 \mathrm{~m}$. We will also make use of the sea surface temperature (SST) data recorded at nominally $1 \mathrm{~m}$ water depth at the lighthouse platform.

\subsection{Auxiliary data}

To integrate the observations of the local glider survey into a larger spatial context, SST and chlorophyll $a$ distributions derived from MODIS satellite data (McClain et al., 2004) were inspected for the period of the glider survey. Considering MODIS Terra and MODIS Aqua products, best data coverage and timing of cloud free conditions were found for the MODIS Terra images for 12 July 2010 (before upwelling) and 16 July 2010 (after upwelling).

\section{Results}

\subsection{High-resolution glider survey (July 2010)}

The parameter distributions (Fig. 2) were constructed from glider profile data operating along a zonal section of about $500 \mathrm{~m}$ length (Fig. 1). In the following we consider the horizontal variability along this section to be insignificant and interpret the data as being representative only for the temporal evolution of the parameter.

A typical summer stratification, with warm, low salinity surface water overlaying colder and more saline deeper water masses, is seen during most of the survey time (Fig. 2a, b). Two upwelling events are clearly visible in all parameter fields. The first upwelling began early on 13 July 2010 (06:00) with a peak on the same day at about 18:00 when the highest surface density of $1009.5 \mathrm{~kg} \mathrm{~m}^{-3}$ was observed. The second event began at early 15 July (00:00) and peaked at 18:00 with an even higher surface density of $1010.7 \mathrm{~kg} \mathrm{~m}^{-3}$. The highest SST (observed at $0.5 \mathrm{~m}$ depth) was recorded in the evening of the 10 July 2010 , when temperatures above $23^{\circ} \mathrm{C}$ were measured. The lowest SST (below $15.1^{\circ} \mathrm{C}$ ) was observed at the peak of the second upwelling event (15 July 2010 18:00 UTC).

The dissolved oxygen concentrations (Fig. 2c) are highest (and close to saturation) in the surface layer and decrease rather linearly with depth. Surface ocean under-saturation (up to $10 \%$ ) was observed during the upwelling. Minimal concentrations of about $120 \mu \mathrm{mol} \mathrm{kg}-1$ are found at the deepest sampled depth during the period of the second upwelling event. The appearance of the low oxygen waters at the bottom during the second upwelling event indicates that the upwelling had an impact on the water column as a whole. 
a)
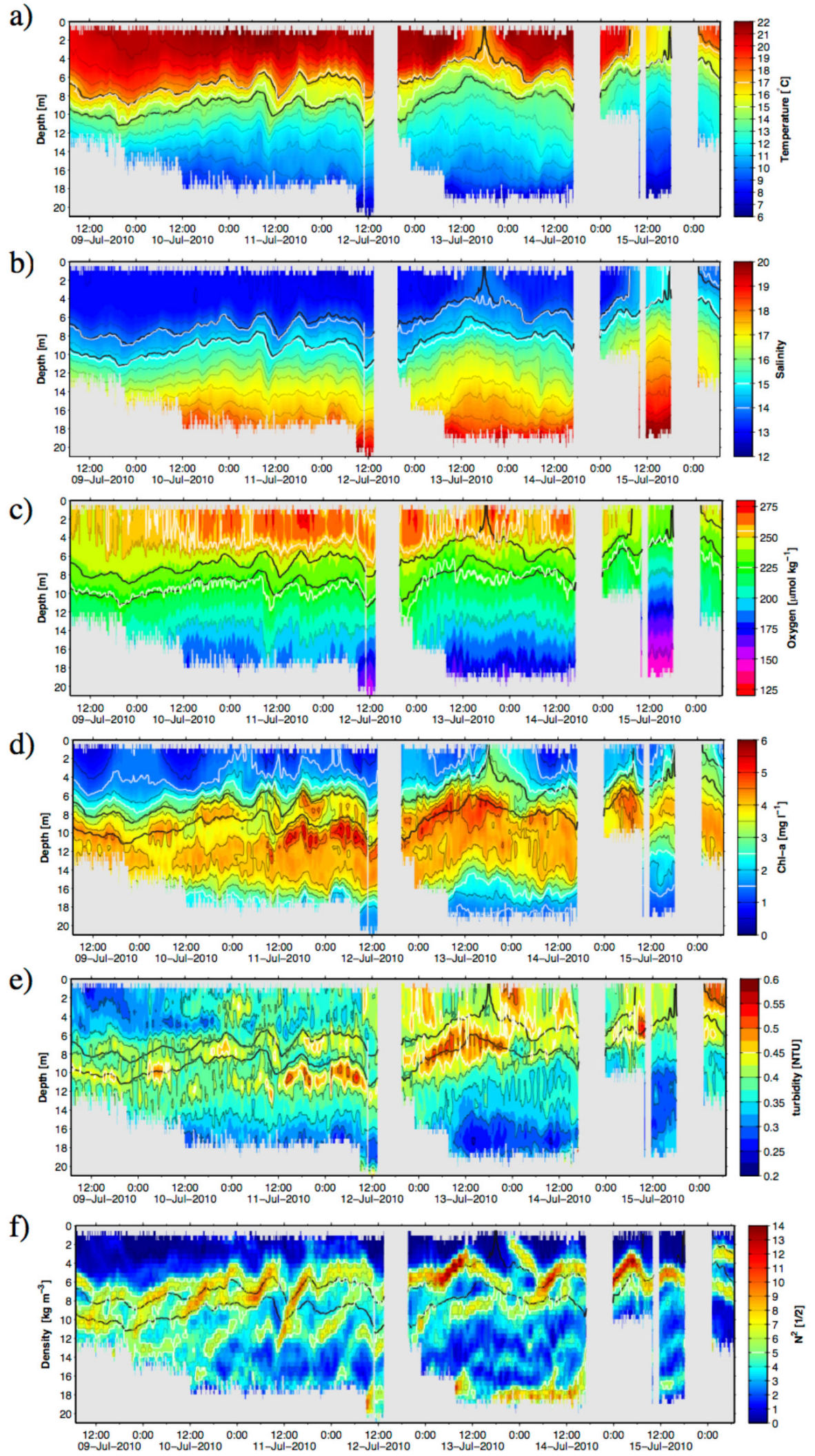

Figure 2. (a) Temperature, (b) salinity, (c) oxygen, (d) chlorophyll a/fluorescence, (e) turbidity and (f) buoyancy frequency from the glider survey. The grey areas indicate no data recordings. The white contours show selected parameter isolines (see individual colour bars). The two outcrop densities 1009.5 and $1010.7 \mathrm{~kg} \mathrm{~m}^{-3}$ are indicted by black lines. 

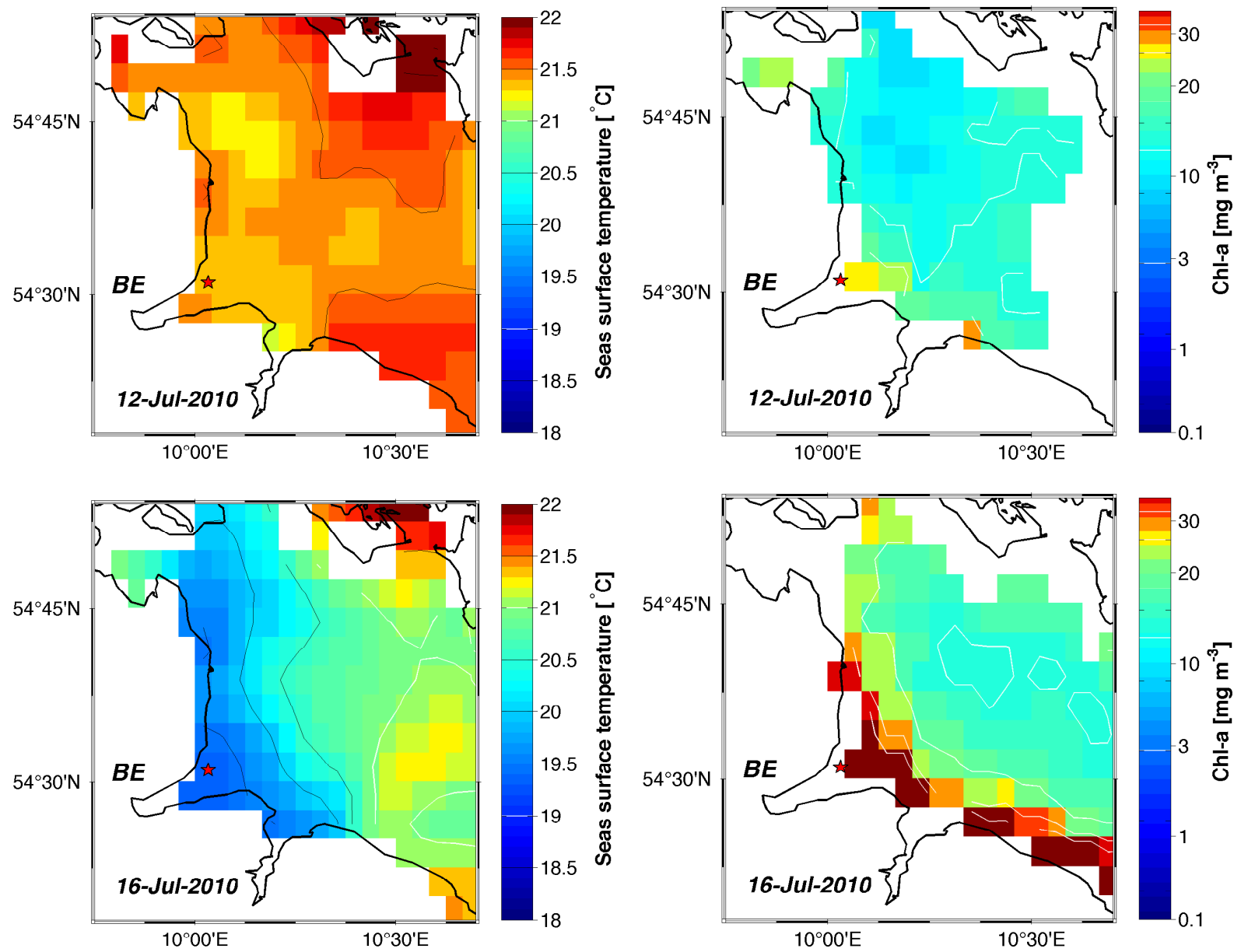

Figure 3. Sea surface temperature (left) and chlorophyll $a$ (right) distribution from MODIS Terra satellite before the two upwelling events (upper) and after the second upwelling (lower). Boknis Eck time-series site is indicated (red star) and labelled (BE).

The chlorophyll $a$ fluorescence ( $\mathrm{Chl} a$ ) is characterized by a subsurface maximum at about $8-12 \mathrm{~m}$ depth (Fig. 2d). Concentrations are very low at the surface, except for the two upwelling events (note, the data are not corrected for any quenching effects). The turbidity distribution (Fig. 2e) resamples mostly the Chl $a$ distribution - noteworthy is the increase in mixed-layer (ML) turbidity after the 12 July 2010.

The buoyancy frequency, as a measure for the vertical stability of the water column (Fig. 2f), showed before the upwelling two stability maxima. One maximum is associated with the base of the ML and is located at about 4-6 m depth; the second is about $2-3 \mathrm{~m}$ deeper and where the transition to the deep waters occurs. The ML was on average about 4 to $6 \mathrm{~m}$ thick but disappeared during the upwelling with the uplift of isopycnals and quickly re-established with the ceasing of the wind and the relaxation of the density field.

From selected satellite maps (Fig. 3) it can be seen that the upwelling had an impact on a much larger area. A pronounced cooling is found along the coastline from Kiel Bay to Åls Island (Denmark). The upwelling front (defined by the strongest horizontal gradient in SST) was located approximately 5 to $10 \mathrm{~km}$ from the western coastline, i.e. the total area under the influence of upwelling was about 400 to $500 \mathrm{~km}^{2}$.

The coldest SST observed with the glider was $3 \mathrm{~K}$ colder than the lowest satellite SST (Fig. 3, left), which most likely is related to the temporal sampling of the satellite as well as to the spatial averaging into pixels $(4 \mathrm{~km})$. Nevertheless, it demonstrates that the resolution of the satellite is not optimal in determining the strength of the SST variability in the region.

Satellite-derived surface Chl $a$ maps (Fig. 3, right) reveal higher values in the upwelling along the coast but also reach further offshore, similar to the SST anomaly signal. The glider BE survey suggests that the Chl $a$ increase is primarily the result of the uplift of the subsurface Chl $a$ maximum (Fig. 2) and not primarily related to enhanced productivity. As the satellite integrates over the optical depth, the glider Chl $a$ concentration cannot directly be compared with the satellite concentrations. 

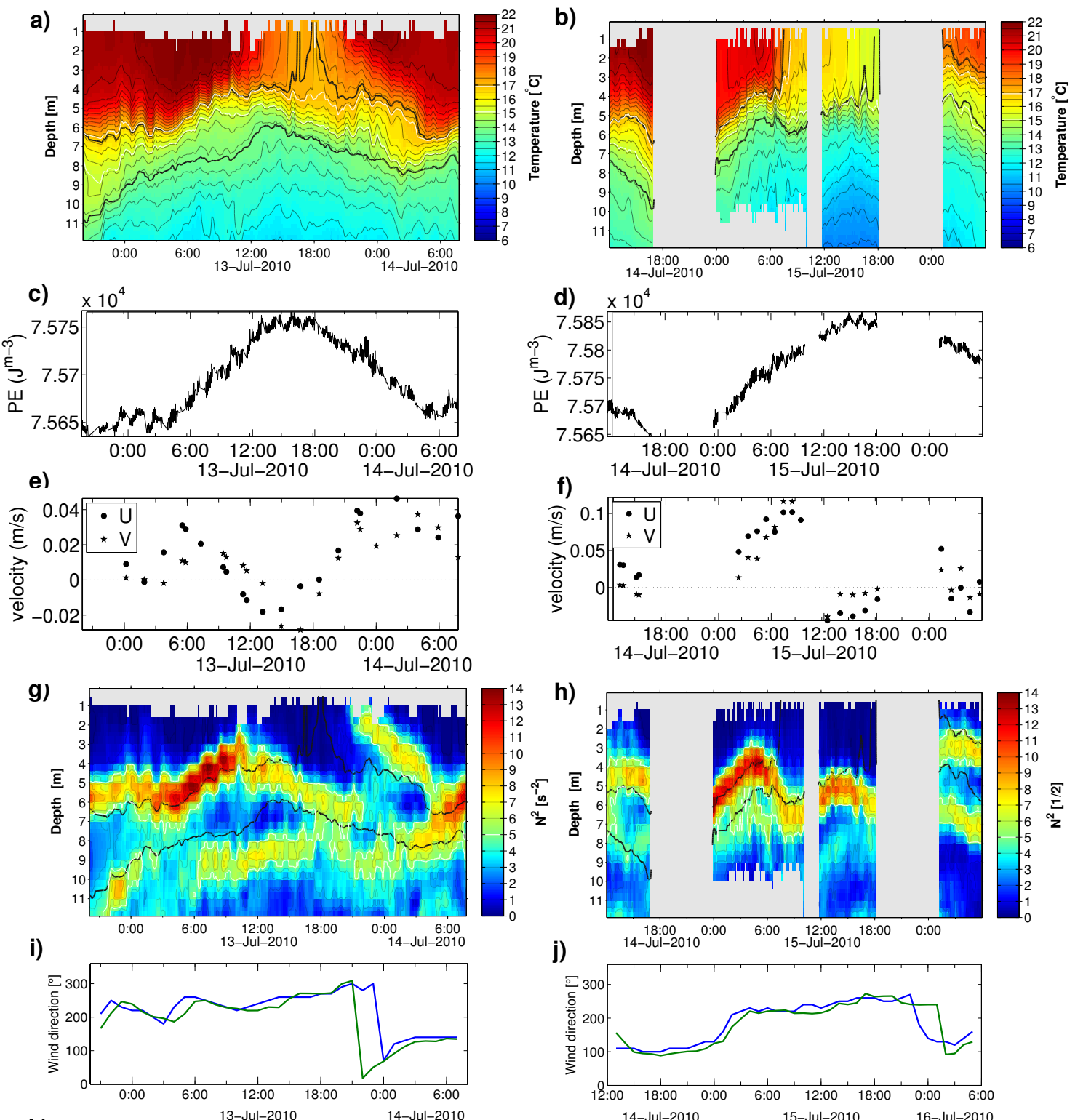

k)
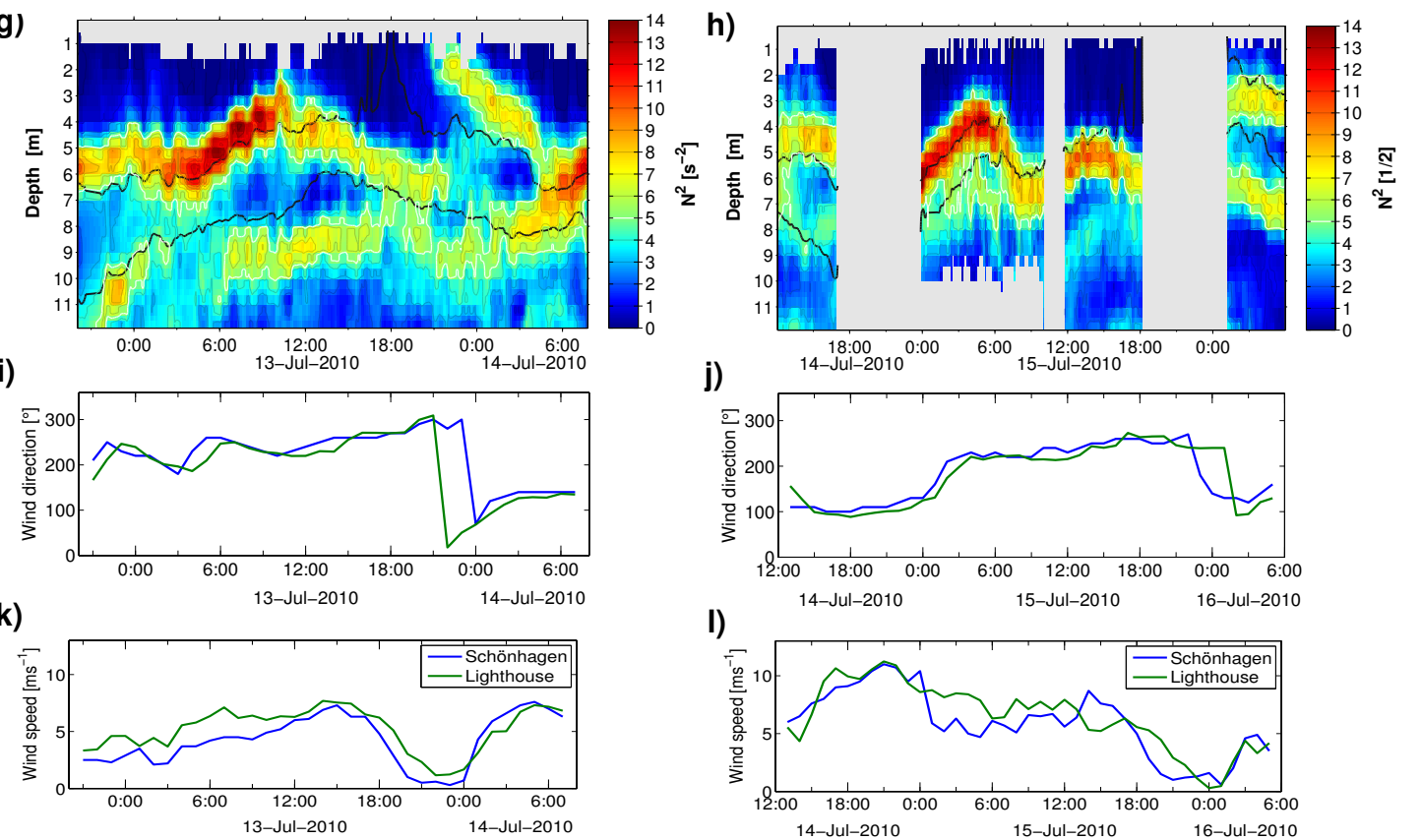

I)

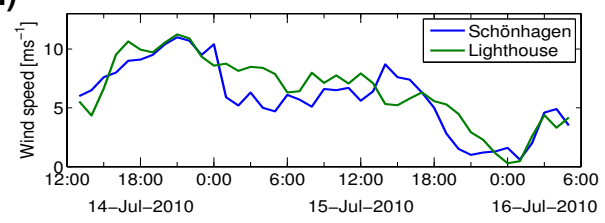

Figure 4. Temporal evolution of selected parameters during the first (left) and second (right) upwelling event. Temperature distribution in the upper $12 \mathrm{~m}(\mathbf{a}, \mathbf{b})$, potential energy of the upper $10 \mathrm{~m}(\mathbf{c}, \mathbf{d})$, vertical integrated velocity from glider $(\mathbf{e}, \mathbf{f})$, buoyancy frequency $(\mathbf{g}, \mathbf{h})$, wind direction at both meteorological stations $(\mathbf{i}, \mathbf{j})$ and wind speed $(\mathbf{k}, \mathbf{l})$.

\subsection{Diagnosis of upwelling from glider data}

Based on the temporal evolution of selected parameters (Fig. 4) we further analysed the upwelling events. Particular interest was devoted to indications for irreversible (diapycnal) mixing associated with these short upwelling events. In order to interpret our time-series data from the glider survey we start with a simple conceptual model view for the wind-driven upwelling on a two-dimensional plane considering only local wind forcing to be important (Gill and Clarke, 1974). The wind stress decreases with distance from the coast and no interior (diapycnal) mixing takes place. In such a case, 
the coastal parallel momentum flux at the surface will force the surface water to flow offshore while in parallel, water within the density range that is successively rising to the surface will be transported onshore. The offshore transport of surface water will lead to a rising of isopycnals that goes along with an increase in potential energy (PE) of the water column. With the ceasing of the momentum input, a reversal of the circulation will set in (onshore flow in the upper layer and offshore flow below) and the original stratification should re-establish. Without any mixing, the final PE should then be similar to the initial PE.

To test whether such a simple model holds for our observations, the potential energy of the water column ( $\mathrm{PE}=\rho g z_{\text {ref }}$; Simpson et al., 1990) was calculated from the in situ density $(\rho)$, gravity $\left(g=9.81 \mathrm{~m} \mathrm{~s}^{-1}\right)$, and a reference depth $\left(z_{\text {ref }}\right)$ chosen to be $8.5 \mathrm{~m}$ which is approximately the "before upwelling" depth of the highest density that outcrops during the second event.

The first event (Fig. 4, see left panels) was forced by a steady increase in wind, starting out of a period of several days with very low wind conditions $\left(<2 \mathrm{~m} \mathrm{~s}^{-1}\right)$. The maximum wind speed during the event was $7 \mathrm{~m} \mathrm{~s}^{-1}$ from southwest $\left(250^{\circ}\right)$, which leads to a maximum increase in PE by about $120 \mathrm{~J} \mathrm{~m}^{-3}\left(\rho=1009.5 \mathrm{~kg} \mathrm{~m}^{-3}\right.$ at $0.5 \mathrm{~m}$ depth at 17:50 UTC). With the relaxation of the upwelling favourable wind forcing, the PE reverted back and close to its initial (before upwelling) value. At most about $10 \%$ (approx. $15 \mathrm{~J} \mathrm{~m}^{-3}$ ) of the energy input was irreversibly transformed to a change in stratification. As such, most wind energy was invested in the lateral movement (offshore/onshore) of the water. Over the period of $18 \mathrm{~h}$ the density surfaces were lifted up (and relaxed back) by $6 \mathrm{~m}$, which translates into a vertical velocity of $8 \mathrm{mday}^{-1}$ (in agreement with earlier studies e.g. Lehmann and Myrberg, 2008). Unfortunately we do not have information about the vertical structure of the flow. The only information we have is the depthintegrated flow, derived from the glider dead reckoning. This flow shows a coherent signal in relation to the upwelling event (Fig. 4e and f). With the onset of the upwelling a depth-averaged (net) offshore flow is seen. This turns into a more southerly flow during the peak upwelling followed by a southeastward offshore flow during the relaxation phase.

The second upwelling event (Fig. 4, see right panels) was driven by a stronger wind forcing. A preconditioning of the water column by the first upwelling event (Myrberg et al., 2010) is limited as the area was under the influence of strong easterly winds (and as such, downwelling favourable winds) the day before. The upwelling event started with a rather abrupt (within 1 hour) turn of the wind to southwesterly directions $\left(250^{\circ}\right)$. The uplift of the density field led to an increase of PE by more than $210 \mathrm{~J} \mathrm{~m}^{-3}$, and water from about $8 \mathrm{~m}$ depth was lifted to the surface (equivalent to a vertical velocity of $10 \mathrm{~m} \mathrm{day}^{-1}$ ). After the relaxation of the density field an irreversible increase in PE by about $140 \mathrm{~J} \mathrm{~m}^{-3}$ ( $\rho=1000.7 \mathrm{~kg} \mathrm{~m}^{-3}$ at $0.5 \mathrm{~m}$ depth at 17:50 UTC) was found, an order of magnitude larger than during the first event. Although it cannot completely be excluded that the glider mission was terminated before the full recovery of the density field, an increase in upper layer salinity by 0.5 (not shown) suggests that significant diapycnal mixing had occurred, and water denser than the outcrop density must have been involved in the mixing to explain the salinity increase. The depth-integrated flow is about twice as large as for the first event. Again a net offshore flow (about $0.1 \mathrm{~m} \mathrm{~s}^{-1}$ ) during the onset of the upwelling is seen followed by a much weaker and onshore flow during the phase when the density field relaxed.

Associated with the upwelling was an increase in the surface water Chl $a$ concentrations (Fig. 3). This increase can be explained, at first order, by the uplift of the subsurface $\mathrm{Chl} a$ maximum. However, along-isopycnal $\mathrm{Chl} a$ concentrations are decreasing during the upwelling (not shown here), which indicates that mixing with deeper water that has a lower $\mathrm{Chl} a$ content has taken place. In general it cannot be excluded that phytoplankton growth (and as such an increase in Chl $a$ ), e.g. stimulated by the entrainment of nutrient-rich water into the euphotic zone, took place in parallel to the dilution. Nevertheless, it was not strong enough to overcome the dilution by upwelling.

For both events it is interesting to note that the stability of the water column at the mixed layer base was enhanced during the uplift of the isopycnals (Fig. 4). The zone of higher stability disappeared when it reached a depth of 2 to $3 \mathrm{~m}$, which we interpret as the depth that is under the direct impact of mechanical stirring from the wind e.g. Langmuir circulation cells (Chubarenko et al., 2010).

\subsection{Identification of summer upwelling events in the BE observational record}

We now utilize the observations from the glider in combination with the wind and SST data to derive statistics for the summer (June to September) upwelling at the BE. Variability in the BE data is a mixture of multiple scales and processes, ranging from diurnal to decadal variability while the seasonal cycle is for many parameters the dominant one. To derive anomalies we first calculated a long-term mean seasonal cycle (Fig. 5) by grouping all BE surveys into monthly bins, considering a surface layer (standard depth $1 \mathrm{~m}$ ) and a bottom layer (standard depth $26 \mathrm{~m}$ or $25 \mathrm{~m}$ ). We consider only the BE surveys in the period that overlap with the time series of meteorological data from Schönhagen (1982 to 2012).

At both BE depth levels a clear seasonal signal is seen for temperature, salinity and oxygen. Maximum temperature in the upper layer is found by the end of summer (August) while in the bottom layer the maximum is shifting towards October because overturning, driven primarily by heat loss at the surface, is required for the downward propagation of warmer waters. Looking more closely, in October the temperature at both levels is rather similar, which indicates that no vertical 

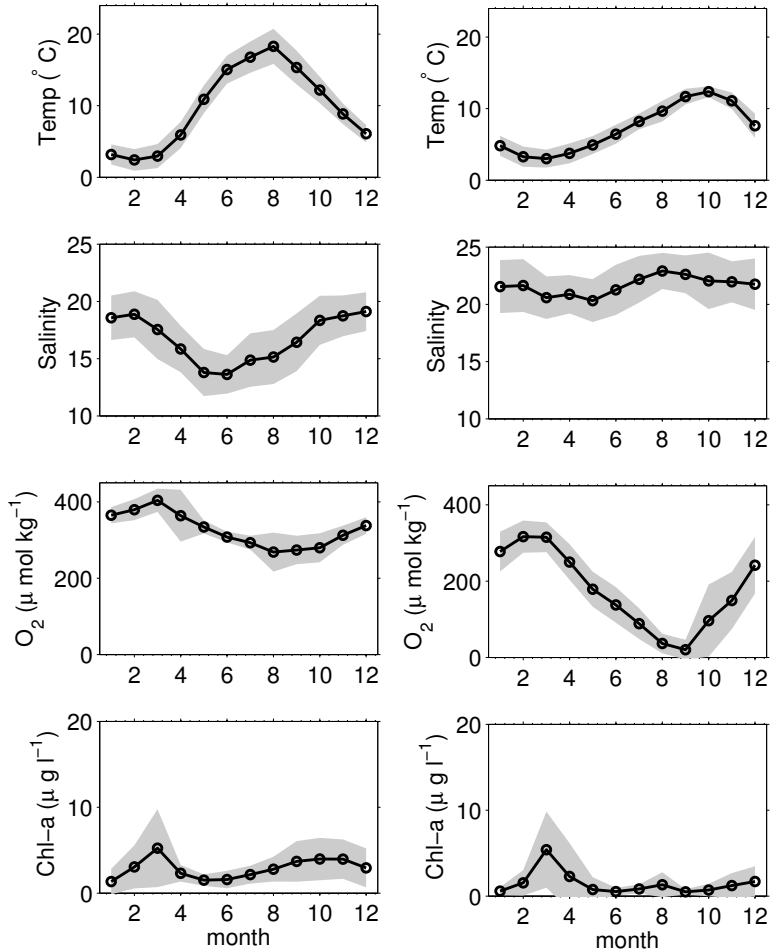

Figure 5. Long-term mean (1982 to 2012) seasonal cycle of BE parameters for all data above $2 \mathrm{~m}$ (left) and below $24 \mathrm{~m}$ (right). Grey shading indicates the standard deviation.

gradient exists. The deep overturn of waters in October also explains why the oxygen concentrations at depth start to rise again - oxygen saturated surface waters are mixed into the more depleted bottom waters through the overturning process. A salinity gradient between upper and bottom layer exists year round, with higher salinities at the deeper level. We expect that this gradient can be sustained year round by a balance of salt supply, from inflowing North Sea water at the bottom, and a net freshwater surplus at the surface, from rain/run-off.

Chlorophyll $a$ in the surface as well as in the deep layer shows a pronounced peak in March (spring bloom). In the surface layer an increase in Chl $a$ is also seen in autumn while in the deep layer concentrations stay low. The variability at the spring bloom peak is large and may have to do with a subsurface $\mathrm{Chl} a$ maximum that is not adequately sampled by the discrete bottle samples (see also Fig. 2e) but also is a sign for pronounced interannual variability. By subtracting the long-term monthly mean averages from individual BE summer surveys, anomalies are calculated (Fig. 6) which show event-type variability.

Through the glider data analysis we determined that summer upwelling was associated with coastal parallel to slightly offshore $\left(210^{\circ}\right.$ to $\left.260^{\circ}\right)$ winds and wind speeds of at least $4 \mathrm{~m} \mathrm{~s}^{-1}$ (averaged hourly). To improve the statistics of possible upwelling favourable conditions we made use of the fact
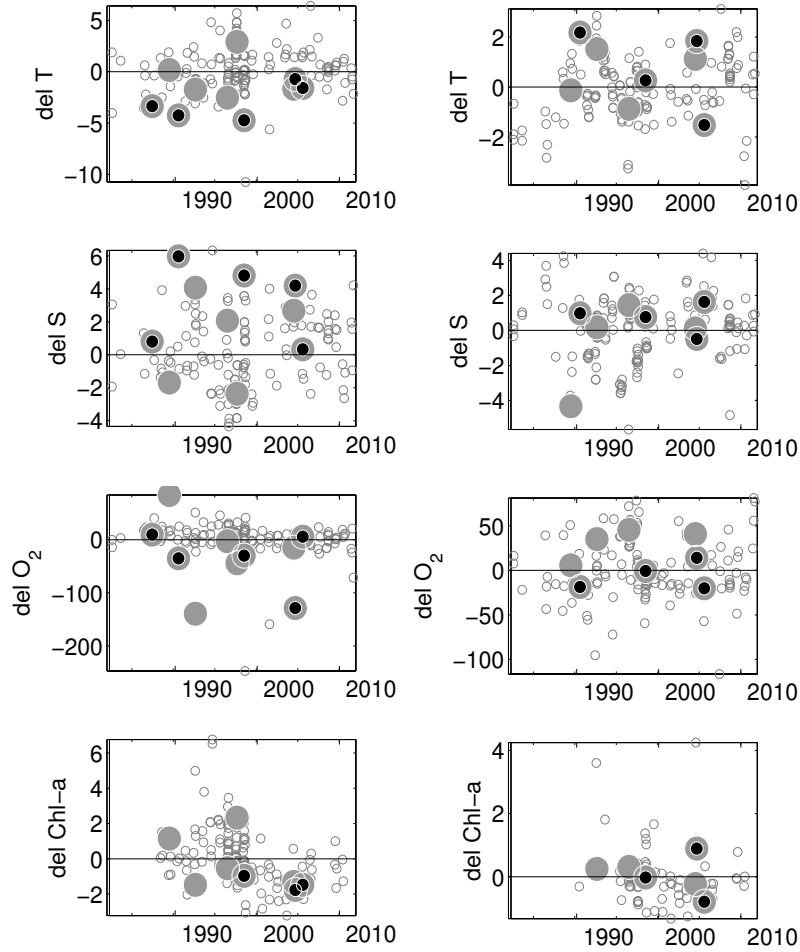

Figure 6. Summer (June to September) anomalies (relative to longterm monthly mean, see Fig. 5) of single BE surveys between 1982 and 2012. Left: averaging all data above $2 \mathrm{~m}$. Right: averaging data below $24 \mathrm{~m}$ (right). Grey (black) dots indicate the anomalies that are associated with the 10 (5) strongest 1.5 day wind impulses (see Table 1).

that local BE site SST cooling during upwelling is not found in concurrent SST cooling at Kiel lighthouse station (Fig. 7, left). Therefore, we used any SST difference between BE surveys and Kiel lighthouse larger than $2 \mathrm{~K}$ as an indicator for active upwelling during the $\mathrm{BE}$ survey. Based on this criterion the directional range of upwelling favourable winds extended to more offshore than coastal-parallel wind directions (190 to $260^{\circ}$ Fig. 7, right), which is also in line with other observations from shallow areas (Walin, 1972; Gill and Clarke, 1974).

The glider survey showed that large and short-term SST anomalies are created even under moderate wind conditions and with only small irreversible changes in the density field. In turn, low resolution (several hours or even days) SST observations help to identify upwelling but do not reflect well the intensity of upwelling. Strength and persistence of the upwelling favourable winds are important control parameters and a practical measure for the time-integrated impact of the wind forcing is the wind impulse ( $I$; Haapala, 1994; Myrberg et al., 2010):

$$
I=\int_{0}^{t} c_{\mathrm{d}} \rho_{\mathrm{a}} U^{2} \mathrm{~d} t,
$$



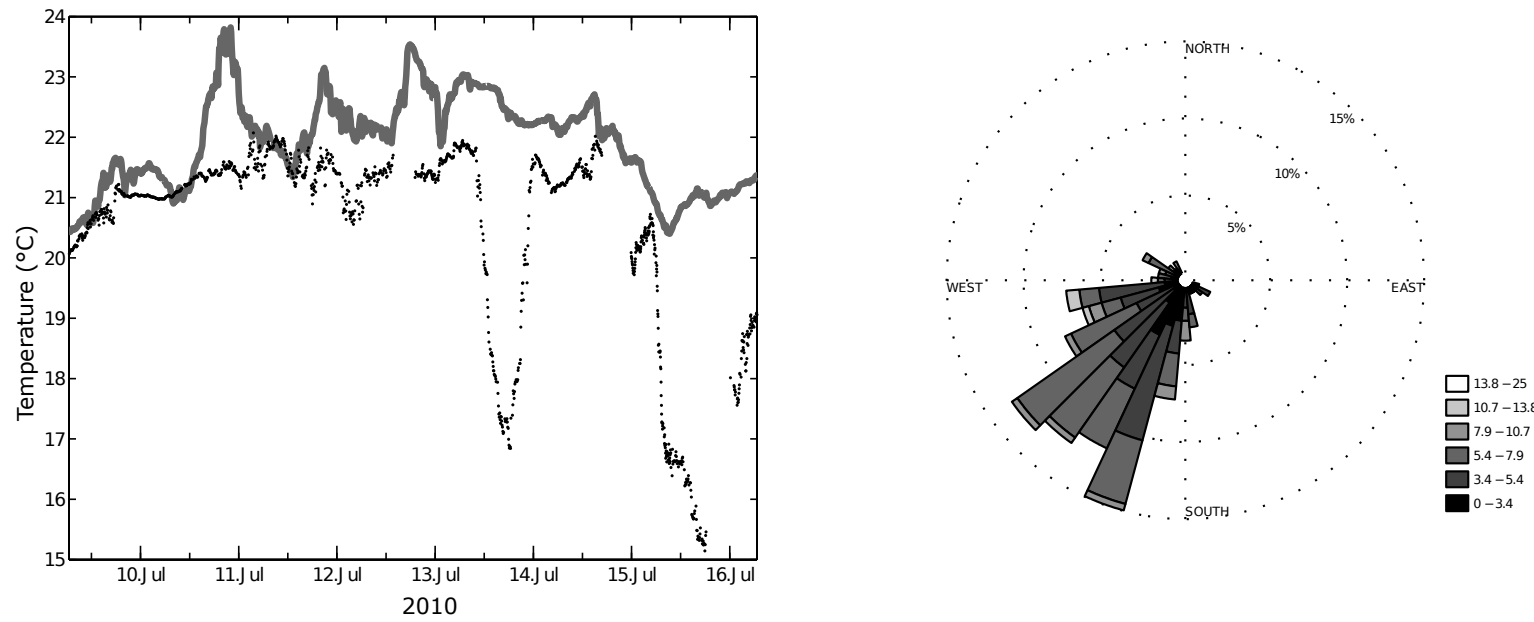

Figure 7. Left: sea surface temperature (at nominal $1 \mathrm{~m}$ depth) recorded at the Kiel lighthouse (grey line) and glider temperature (black dots) (observation closest to the surface at typically 0.5 to $1 \mathrm{~m}$ depth). Right: wind rose plot of Schönhagen wind taking into account all data within $12 \mathrm{~h}$ before an SST difference between Kiel lighthouse and BE survey of larger $2 \mathrm{~K}$ was detected (considering the period 1988 to 2012 ).

where $c_{\mathrm{d}}$ is the drag coefficient (Large and Pond, 1981), $\rho_{\mathrm{a}}$ is the air density $\left(1.2 \mathrm{~kg} \mathrm{~m}^{-3}\right)$ and $U$ is the wind speed at $10 \mathrm{~m}$.

Inspecting now only upwelling favourable wind direction and speed combinations in the Schönhagen wind data (1982 to 2012) revealed that on average about 18 days (based on cumulative sum of hours) of upwelling favourable wind situations are present at BE each summer (Fig. 8). The three years with most upwelling favourable winds include 1985 (28.7 days), 1988 (28 days), and 1998 (27.75 days) while the three years with the least upwelling favourable winds were 2006 (7.6 days), 1989 (10.2 days), and 1997 (12.5 days).

Comparing SST difference (1988 to 2012 data) and wind impulse (1982 to 2012) for all summer BE surveys (Fig. 9) reveal that wind intensity and SST anomaly do not correlate well. In fact many BE surveys that do not show a pronounced SST anomaly are recorded after intense wind impulse. One reason for underestimating the SST amplitude is to be expected from the coarse sampling of SST during the survey, whereas the high resolution glider survey showed that the SST quickly relaxes back with the ceasing of the wind. Moreover, the mismatch in SST and wind impulse may also indicate that the upwelling affected a large area of the Belt Sea including Kiel lighthouse and as such damped the SST anomaly between lighthouse and BE survey.

The time series of upper- and lower-layer parameter anomalies in the summer month BE time series show a pattern that can be explained by considering the strength of the wind impulse before the survey (Fig. 6; grey and black dots indicate strongest wind impulses listed in Table 1). Strong wind impulse before a BE survey causes lower temperatures, higher salinity, lower oxygen and maybe lower Chl $a$ in the surface waters. For the deep waters the upwelling is associated with higher salinities and higher oxygen content, while $\mathrm{Chl} a$ and temperature are indifferent. When interpreting sin-

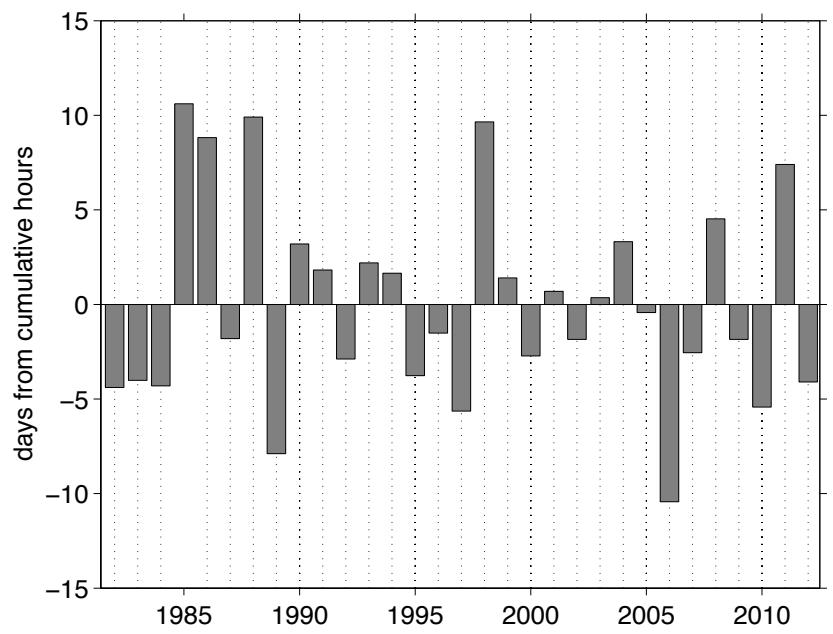

Figure 8. Anomalous days (from cumulative sum of hours) of upwelling favourable winds (see text for definition) per year from summer (June to September) hourly observations recorded at Schönhagen station 1982 to 2012 (compare Fig. 1). Mean is 18.1 days.

gle surveys of other parameters recorded at BE it may be of use to consider the wind impulse strength before a certain experiment in order to take the impact of upwelling into account (see Table A1 for a complete list of wind impulses for BE summer surveys).

\section{Conclusions}

High-resolution glider observation recorded over 7 days in July 2010 enabled us to analyse two summer upwelling events in the western Baltic in the vicinity of the Boknis Eck 
Table 1. Twenty most significant summer (June to September) upwelling events in relation to BE surveys (1982-2012) ordered by wind impulse per day (over a period of 1.5 days before the BE survey). The temperature difference between Kiel lighthouse and the BE survey as well as the wind impulse per day based on the 3.5 days before the BE survey and estimate from Schönhagen wind data are given. The top five events in each category are weighted bold. For reference the intensity as calculated for the glider survey is given at the end of the table.

\begin{tabular}{|c|c|c|c|}
\hline $\begin{array}{l}\text { Date } \\
(\mathrm{dd} / \mathrm{mm} / \text { yyyy })\end{array}$ & $\begin{array}{r}\text { Wind impulse } \\
(1.5 \text { days }) \\
\left(\mathrm{kg} \mathrm{m}^{-1}\right. \\
\left.\mathrm{s}^{-1} \text { day }^{-1}\right)\end{array}$ & $\begin{array}{r}\text { SST } \\
\text { difference } \\
(\mathrm{K})\end{array}$ & $\begin{array}{r}\text { Wind impulse } \\
\text { (3.5 days) } \\
\left(\mathrm{kg} \mathrm{m}^{-1}\right. \\
\left.\mathrm{s}^{-1} \text { day }^{-1}\right)\end{array}$ \\
\hline $21 / 08 / 1990$ & 10475 & -2.50 & 13692 \\
\hline $18 / 06 / 1987$ & 10318 & -0.15 & 13811 \\
\hline $15 / 07 / 1998$ & 7161 & -4.64 & 13122 \\
\hline $13 / 09 / 2004$ & 7069 & -2.58 & 10040 \\
\hline $11 / 08 / 2005$ & 6021 & -0.54 & 8059 \\
\hline 03/09/1992 & 5750 & -2.40 & 8809 \\
\hline $13 / 07 / 2004$ & 5250 & -0.29 & 10674 \\
\hline 08/09/1997 & 5073 & -0.95 & 7888 \\
\hline $13 / 07 / 1989$ & 4760 & -1.86 & 7994 \\
\hline $11 / 07 / 1996$ & 4634 & 0.25 & 5203 \\
\hline $15 / 07 / 1999$ & 4610 & -0.30 & 6121 \\
\hline 27/08/1992 & 4524 & -1.46 & 6967 \\
\hline 06/08/1992 & 4231 & -3.40 & 7718 \\
\hline $21 / 09 / 2011$ & 4186 & -2.69 & 7335 \\
\hline 09/08/2001 & 3720 & -5.06 & 4793 \\
\hline $12 / 07 / 2007$ & 3708 & $\mathrm{NaN}$ & 5285 \\
\hline 09/07/2008 & 3664 & -4.17 & 5608 \\
\hline $28 / 06 / 2000$ & 3444 & $\mathrm{NaN}$ & 4518 \\
\hline $22 / 07 / 1998$ & 3183 & -1.51 & 4947 \\
\hline $21 / 06 / 2011$ & 3126 & -2.14 & 4904 \\
\hline \multicolumn{4}{|l|}{ Glider } \\
\hline $13 / 07 / 2010$ & 1632 & -5 & 838 \\
\hline $15 / 07 / 2010$ & 2457 & -6 & 1679 \\
\hline
\end{tabular}

time-series station. By using nearby meteorological station wind data we were able to derive the specific wind forcing conditions that triggered the two summer upwelling events that we identified in the glider data.

The first upwelling was initiated by a rather continuous increase in wind to moderate speed (4 to $6 \mathrm{~m} \mathrm{~s}^{-1}$ from $270^{\circ}$ ). Comparing the hydrographic structure before and after the event, no significant changes were observed and as such vertical/diapycnal mixing is assumed to be small. Water from approximately $6 \mathrm{~m}$ depth was brought to the surface and a significant surface temperature drop by $5 \mathrm{~K}$ was observed. The second upwelling event was initiated by a change in wind direction, from a moderate onshore wind $\left(10 \mathrm{~m} \mathrm{~s}^{-1}, 100^{\circ}\right)$ to an offshore wind $\left(6 \mathrm{~m} \mathrm{~s}^{-1}, 210^{\circ}\right)$. The SST dropped by up to $5.6 \mathrm{~K}$ and comparing the upper layer salinity before and after the upwelling we conclude that water from below $10 \mathrm{~m}$ must have been incorporated into the

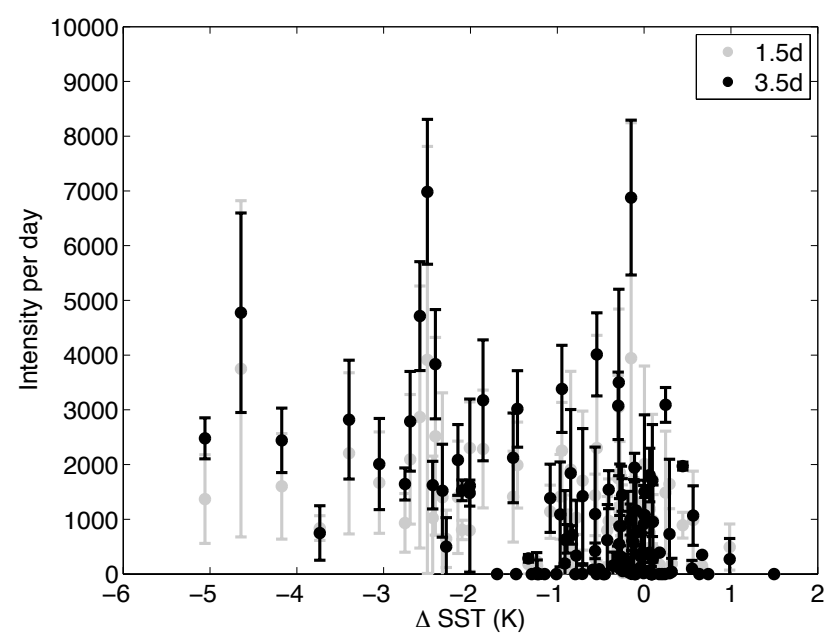

Figure 9. Wind impulse per day over the 1.5 and 3.5 days before the individual BE survey versus SST difference between Kiel lighthouse and BE surveys between 1988 and 2012 (compare also Table A1). The standard deviation in wind impulse over the respective periods ( 1.5 and 3.5 days) is indicated by the error bars (see Table 1 for details on most extreme events). Note that events without SST anomaly are not shown in this figure but in Table 1 .

upwelling. For both events depth-integrated currents indicate a change in offshore/onshore flow associated with the upwelling/relaxation of the density field during/after the wind forcing.

In particular for the first event the similarity of the stratification before and after the event is remarkable and supports the idea of a simple two-dimensional offshore/onshore circulation scheme becoming established by the wind. A stronger forcing during the second event resulted in diapycnal mixing. It is possible that deeper layer waters, which upwelled closer to the coast (e.g. seen in the temperature gradient normal to the coast, Fig. 3), were pushed on top of the lighter water when it was advected offshore (e.g. Reissmann et al., 2009) and the resulting overturn, enhanced by wind stirring, can result in diapycnal mixing.

Our analysis shows that at BE the most favourable wind direction for upwelling is southerly $\left(190^{\circ}\right)$ to westerly $\left(260^{\circ}\right)$ winds and that wind speed should exceed $4 \mathrm{~m} \mathrm{~s}^{-1}$. The BE site faces open waters to the north and east and as such the upwelling would follow the Ekman theory concept of coastal parallel winds for a spectrum of directions. Nevertheless, an upwelling that is forced by winds normal to the coast ("Leewirkung"; Myrberg and Andrejev, 2003 but also mentioned by Walin, 1972) is likely to operate because of the shallow water depth. Saderne et al. (2013) also observed an upwelling event initiated by westerly winds in the Eckernförde Bay.

By using the wind time series that goes back to 1982 from the meteorological station nearby BE the wind impulse time series is used to reconstruct the possible wind-induced 


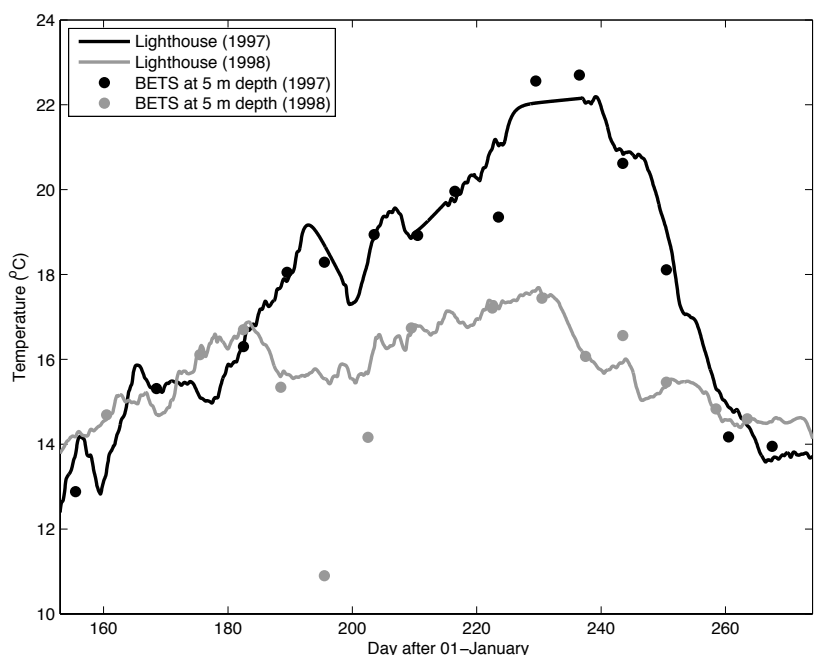

Figure 10. Near-surface temperature time series (1 June to 30 September) from Kiel lighthouse for a selected year with high (1998) and with low frequent upwelling (1997) wind conditions. Dots indicate the respective BE temperature record (15 surveys in 1998, 14 surveys in 1997).

upwelling intensity on the summer BE surveys. Many event type anomalies (mean seasonal cycle removed) are aligned with periods of large wind impulse, which confirm that wind persistence is important for reorganization of the water column (Myrberg et al., 2010). SST anomalies are not well correlated with wind impulse which confirms that the SST anomaly is not a good indicator for the intensity of upwelling. Nevertheless, it is a good indicator for its existence (Bednorz et al., 2013; Lehmann et al., 2012). Not all BE anomaly events can be related to local wind-induced upwelling, and remotely forced upwelling through the propagation of coastal Kelvin waves are possible other drivers.
The interannual variability in wind-induced upwelling at BE is large, ranging from only 7.7 days (2006) to more than 28 days (1985). Comparing the SST time series from the Kiel lighthouse station (Fig. 10) for a year with frequent upwelling $(1998 ; 27.8$ days) with a year with less frequent upwelling (1997; 12.5 days) shows much lower SST in summer for the upwelling favourable year. As Kiel lighthouse is more than $7 \mathrm{~km}$ away from the coast, the local SST is not under direct control of upwelling favourable winds (see also Fig. 7, left) but more representative for the open waters. Siegel et al. (2006) have shown that summer SST in the whole Baltic Sea was one of the highest/lowest in 1997 and 1998 (within the period 1990-2004), respectively. Thus it is important to bear in mind that upwelling favourable winds prevail in the $\mathrm{BE}$ area, when generally colder summers occur in the whole Baltic Sea region.

From a technology point of view we were able to demonstrate that an autonomous glider can be navigated in the shallow Belt Sea, which has a comparably large vertical density gradient. It can provide high temporal and spatial resolved data to support time-series data interpretation. The monthly ship visits make it possible to collect many other parameters, not accessible by autonomous instrumentation. For future missions it has to be considered that this study was carried out in a restricted area and as such the glider's navigation was unaffected by ship traffic. This is only in selected areas of the Baltic Sea the case - for instance 57000 ships pass Fehmarn Belt and another 54000 Öresund Strait every year (HELCOM, 2010) and special attention must be given to ship avoidance strategies when surveying such areas (Merckelbach, 2013). 


\section{Appendix A}

Table A1. Wind impulse per day for BE summer (June to September) surveys between 1982 to 2012. The sea surface temperature (SST) difference between Kiel lighthouse and all BE surveys is given for the period 1988 to 2012 only. For some surveys the SST difference could not be derived (indicated by n.a., not available).

\begin{tabular}{|c|c|c|c|}
\hline $\begin{array}{l}\text { Date } \\
\text { (dd/mm/yyyy) }\end{array}$ & $\begin{array}{r}\text { Wind impulse } \\
(1.5 \text { days }) \\
\left(\mathrm{kg} \mathrm{m}^{-1}\right. \\
\left.\mathrm{s}^{-1} \text { day }^{-1}\right)\end{array}$ & $\begin{array}{r}\text { SST } \\
\text { difference } \\
(\mathrm{K})\end{array}$ & $\begin{array}{r}\text { Wind impulse } \\
(3.5 \text { days }) \\
\left(\mathrm{kg} \mathrm{m}^{-1}\right. \\
\left.\mathrm{s}^{-1} \text { day }^{-1}\right)\end{array}$ \\
\hline 21/08/1990 & 10475 & -2.50 & 13692 \\
\hline 18/06/1987 & 10318 & -0.15 & 13811 \\
\hline 15/07/1998 & 7161 & -4.64 & 13122 \\
\hline $13 / 09 / 2004$ & 7069 & -2.58 & 10040 \\
\hline $11 / 08 / 2005$ & 6021 & -0.54 & 8059 \\
\hline 03/09/1992 & 5750 & -2.40 & 8809 \\
\hline $13 / 07 / 2004$ & 5250 & -0.29 & 10674 \\
\hline 08/09/1997 & 5073 & -0.95 & 7888 \\
\hline 13/07/1989 & 4760 & -1.86 & 7994 \\
\hline 11/07/1996 & 4634 & 0.25 & 5203 \\
\hline 15/07/1999 & 4610 & -0.30 & 6121 \\
\hline 27/08/1992 & 4524 & -1.46 & 6967 \\
\hline 06/08/1992 & 4231 & -3.40 & 7718 \\
\hline $21 / 09 / 2011$ & 4186 & -2.69 & 7335 \\
\hline 09/08/2001 & 3720 & -5.06 & 4793 \\
\hline $12 / 07 / 2007$ & 3708 & n.a. & 5285 \\
\hline 09/07/2008 & 3664 & -4.17 & 5608 \\
\hline $28 / 06 / 2000$ & 3444 & n.a. & 4518 \\
\hline 22/07/1998 & 3183 & -1.51 & 4947 \\
\hline $21 / 06 / 2011$ & 3126 & -2.14 & 4904 \\
\hline $11 / 07 / 2001$ & 3014 & -3.05 & 5844 \\
\hline $14 / 09 / 2005$ & 2958 & 0.45 & 3121 \\
\hline 12/09/1996 & 2917 & -0.11 & 3633 \\
\hline $12 / 08 / 1985$ & 2877 & n.a. & 4110 \\
\hline 09/06/1986 & 2834 & n.a. & 4394 \\
\hline $21 / 09 / 2010$ & 2763 & -0.85 & 6670 \\
\hline 16/09/1998 & 2713 & 0.06 & 4190 \\
\hline $16 / 07 / 1985$ & 2612 & n.a. & 4075 \\
\hline 10/06/1998 & 2563 & 0.10 & 6079 \\
\hline $25 / 09 / 1985$ & 2553 & n.a. & 3139 \\
\hline $16 / 08 / 2007$ & 2468 & -2.75 & 3267 \\
\hline 17/08/1992 & 2435 & -2.44 & 3577 \\
\hline $25 / 07 / 2011$ & 2422 & -2.01 & 8055 \\
\hline 09/09/1992 & 2312 & -0.41 & 3399 \\
\hline 08/06/1995 & 2295 & -2.10 & 2817 \\
\hline $24 / 06 / 2008$ & 2283 & -2.32 & 4907 \\
\hline 16/09/1987 & 2254 & 0.00 & 7023 \\
\hline $19 / 08 / 2008$ & 2218 & -2.01 & 2782 \\
\hline 15/09/1986 & 2211 & n.a. & 2653 \\
\hline $21 / 06 / 2006$ & 2167 & -0.25 & 3020 \\
\hline 18/09/1997 & 2134 & -0.71 & 5971 \\
\hline 02/08/1996 & 2076 & -1.08 & 3984 \\
\hline $12 / 08 / 1982$ & 2021 & n.a. & 3614 \\
\hline 23/08/1993 & 1838 & n.a. & 4070 \\
\hline
\end{tabular}

Table A1. Continued.

\begin{tabular}{|c|c|c|c|}
\hline $\begin{array}{l}\text { Date } \\
\text { (dd/mm/yyyy) }\end{array}$ & $\begin{array}{r}\text { Wind impulse } \\
(1.5 \text { days }) \\
\left(\mathrm{kg} \mathrm{m}^{-1}\right. \\
\left.\mathrm{s}^{-1} \mathrm{day}^{-1}\right)\end{array}$ & $\begin{array}{r}\text { SST } \\
\text { difference } \\
(\mathrm{K})\end{array}$ & $\begin{array}{r}\text { Wind impulse } \\
(3.5 \text { days }) \\
\left(\mathrm{kg} \mathrm{m}^{-1}\right. \\
\left.\mathrm{s}^{-1} \text { day }^{-1}\right)\end{array}$ \\
\hline $13 / 07 / 1993$ & 1831 & n.a. & 3114 \\
\hline 19/08/1998 & 1742 & -0.09 & 4357 \\
\hline 17/06/1991 & 1646 & -0.56 & 5029 \\
\hline 21/07/1988 & 1634 & -0.97 & 4938 \\
\hline $26 / 08 / 1998$ & 1621 & -0.00 & 3198 \\
\hline 10/09/1991 & 1610 & 0.01 & 2667 \\
\hline $14 / 06 / 2007$ & 1603 & 0.56 & 3459 \\
\hline 24/08/1982 & 1596 & n.a. & 3149 \\
\hline 05/06/1996 & 1493 & -0.16 & 2206 \\
\hline 14/08/1991 & 1429 & 0.10 & 3418 \\
\hline 17/08/1999 & 1370 & -0.00 & 3845 \\
\hline 08/07/1998 & 1316 & -0.26 & 4363 \\
\hline 27/06/1996 & 1312 & -0.28 & 3018 \\
\hline 20/06/1988 & 1170 & -0.08 & 1426 \\
\hline $22 / 08 / 1988$ & 1123 & -3.74 & 2938 \\
\hline 21/06/1994 & 1095 & 0.29 & 5753 \\
\hline 27/07/1994 & 1071 & -0.83 & 1410 \\
\hline 24/09/1992 & 1070 & -0.12 & 1119 \\
\hline 05/06/1997 & 965 & -0.89 & 1719 \\
\hline 04/07/1996 & 937 & -0.91 & 3679 \\
\hline 14/09/1988 & 927 & -0.42 & 2800 \\
\hline 21/07/1986 & 888 & n.a. & 2091 \\
\hline $30 / 07 / 1997$ & 856 & -0.12 & 4668 \\
\hline 13/09/1995 & 821 & -0.29 & 1766 \\
\hline $14 / 07 / 2009$ & 751 & -2.28 & 2251 \\
\hline $14 / 06 / 1993$ & 731 & n.a. & 1306 \\
\hline $12 / 07 / 2000$ & 719 & n.a. & 1104 \\
\hline 25/07/1996 & 634 & -0.56 & 1004 \\
\hline $28 / 06 / 2001$ & 587 & 0.18 & 588 \\
\hline 18/06/1997 & 585 & 0.06 & 2637 \\
\hline 18/09/1990 & 554 & 0.01 & 771 \\
\hline 13/07/1995 & 523 & 0.67 & 523 \\
\hline 02/07/1997 & 512 & -0.05 & 1154 \\
\hline $18 / 06 / 2002$ & 500 & -0.78 & 3593 \\
\hline 18/09/1994 & 492 & -0.28 & 6486 \\
\hline 05/06/1985 & 490 & n.a. & 541 \\
\hline 02/07/1998 & 470 & -0.03 & 1405 \\
\hline 17/09/1999 & 437 & n.a. & 517 \\
\hline $10 / 08 / 2010$ & 429 & -1.33 & 628 \\
\hline 17/09/2002 & 413 & n.a. & 813 \\
\hline 29/07/1998 & 408 & 0.10 & 499 \\
\hline 16/06/1992 & 407 & 0.98 & 1726 \\
\hline 17/08/1994 & 337 & -0.19 & 3031 \\
\hline 27/08/1989 & 289 & -0.30 & 969 \\
\hline 07/08/1986 & 288 & n.a. & 3146 \\
\hline 01/08/2011 & 288 & -0.91 & 370 \\
\hline $28 / 07 / 2005$ & 275 & -0.27 & 1498 \\
\hline 08/08/1996 & 257 & n.a. & 294 \\
\hline 22/07/1991 & 227 & -0.36 & 992 \\
\hline $10 / 09 / 2001$ & 175 & -0.04 & 1617 \\
\hline $17 / 06 / 2003$ & 175 & -0.29 & 1110 \\
\hline 17/09/1992 & 162 & -0.28 & 3580 \\
\hline
\end{tabular}


Table A1. Continued.

\begin{tabular}{|c|c|c|c|}
\hline $\begin{array}{l}\text { Date } \\
\text { (dd/mm/yyyy) }\end{array}$ & $\begin{array}{r}\text { Wind impulse } \\
(1.5 \text { days }) \\
\left(\mathrm{kg} \mathrm{m}^{-1}\right. \\
\left.\mathrm{s}^{-1} \text { day }^{-1}\right)\end{array}$ & $\begin{array}{r}\text { SST } \\
\text { difference } \\
(\mathrm{K})\end{array}$ & $\begin{array}{r}\text { Wind impulse } \\
\text { (3.5 days) } \\
\left(\mathrm{kg} \mathrm{m}^{-1}\right. \\
\left.\mathrm{s}^{-1} \text { day }^{-1}\right)\end{array}$ \\
\hline 09/07/2002 & 158 & n.a. & 999 \\
\hline 01/09/1997 & 157 & -0.22 & 902 \\
\hline 19/06/1990 & 148 & n.a. & 2449 \\
\hline $25 / 08 / 1997$ & 146 & 0.55 & 523 \\
\hline 17/06/1999 & 132 & -0.52 & 137 \\
\hline 01/07/2010 & 114 & -0.59 & 228 \\
\hline $27 / 09 / 2000$ & 100 & n.a. & 118 \\
\hline 26/09/1996 & 96 & -0.12 & 96 \\
\hline $21 / 06 / 2005$ & 81 & -0.25 & 81 \\
\hline $25 / 09 / 1997$ & 59 & 0.32 & 658 \\
\hline 23/08/1995 & 52 & -0.18 & 52 \\
\hline 15/08/1996 & 36 & n.a. & 46 \\
\hline $25 / 06 / 1998$ & 31 & -0.14 & 1862 \\
\hline 20/08/2009 & 31 & -1.24 & 811 \\
\hline 18/07/1996 & 22 & -0.01 & 133 \\
\hline $13 / 08 / 2003$ & 21 & 0.29 & 44 \\
\hline 08/09/2003 & 9 & 0.08 & 25 \\
\hline $23 / 06 / 2009$ & 6 & -0.71 & 360 \\
\hline 11/08/1998 & 1 & -0.14 & 886 \\
\hline 28/08/1983 & 0 & n.a. & 66 \\
\hline 13/06/1989 & 0 & -0.55 & 36 \\
\hline 12/09/1989 & 0 & -0.11 & 0 \\
\hline 19/07/1990 & 0 & 0.08 & 142 \\
\hline 16/09/1993 & 0 & n.a. & 0 \\
\hline 21/08/1996 & 0 & 1.50 & 0 \\
\hline 29/08/1996 & 0 & 0.17 & 174 \\
\hline 19/09/1996 & 0 & -0.10 & 0 \\
\hline 09/07/1997 & 0 & 0.21 & 0 \\
\hline 15/07/1997 & 0 & n.a. & 84 \\
\hline 23/07/1997 & 0 & 0.09 & 0 \\
\hline 05/08/1997 & 0 & 0.24 & 66 \\
\hline $12 / 08 / 1997$ & 0 & -1.69 & 0 \\
\hline 18/08/1997 & 0 & n.a. & 136 \\
\hline 01/09/1998 & 0 & 0.64 & 50 \\
\hline 08/09/1998 & 0 & 0.10 & 0 \\
\hline 21/09/1998 & 0 & 0.08 & 390 \\
\hline $20 / 08 / 2002$ & 0 & n.a. & 0 \\
\hline $15 / 07 / 2003$ & 0 & -1.23 & 505 \\
\hline $10 / 08 / 2004$ & 0 & 0.74 & 0 \\
\hline $27 / 07 / 2006$ & 0 & -0.45 & 4 \\
\hline $12 / 09 / 2007$ & 0 & -0.79 & 0 \\
\hline $15 / 09 / 2008$ & 0 & -1.29 & 0 \\
\hline $16 / 09 / 2008$ & 0 & -1.47 & 0 \\
\hline 17/09/2008 & 0 & -1.15 & 0 \\
\hline $18 / 09 / 2008$ & 0 & -1.21 & 0 \\
\hline 15/09/2009 & 0 & -1.01 & 0 \\
\hline 02/06/2010 & 0 & -0.47 & 0 \\
\hline
\end{tabular}


Acknowledgements. We thank the crew from RB Polarfuchs and M. Schlundt for assistance in the glider operations at sea, J. Herford for assistance in the data preparation, and $\mathrm{H}$. Bange for providing the $\mathrm{BE}$ data and organizing the $\mathrm{BE}$ site. The research leading to these results have received funding from the European Union 7th Framework Programme (FP7 2007-2013), under grant agreement no. 284321 GROOM (www.groom-fp7.eu) and by EGO-COST Action ES0904.

The service charges for this open access publication have been covered by a Research Centre of the Helmholtz Association.

Edited by: H. Bange

\section{References}

Bange, H. W., Bergmann, K., Hansen, H. P., Kock, A., Koppe, R., Malien, F., and Ostrau, C.: Dissolved methane during hypoxic events at the Boknis Eck time series station (Eckernförde Bay, SW Baltic Sea), Biogeosciences, 7, 1279-1284, doi:10.5194/bg7-1279-2010, 2010.

Bange, H. W., Hansen, H.-P., Malien, F., Lass, K., Dale, A., Karstensen, J., Petereit, C., and Friedrichs, G.: Boknis Eck Time Series Station (SW Baltic Sea): Measurements from 1957 to 2010, LOICZ Inprint, ISSN 2070-2442, 1, 16-22, 2011.

Bednorz, E., Polrolniczak, M., and Czernecki, B.: Synoptic conditions governing upwelling along the Polish Baltic coast, Oceanologia, 55, 767-785, 2013.

Bertics, V. J., Löscher, C. R., Salonen, I., Dale, A. W., Gier, J., Schmitz, R. A., and Treude, T.: Occurrence of benthic microbial nitrogen fixation coupled to sulfate reduction in the seasonally hypoxic Eckernförde Bay, Baltic Sea, Biogeosciences, 10, 1243-1258, doi:10.5194/bg-10-1243-2013, 2013.

Chubarenko, I., Chubarenko, B., Esiukova, E., and Baudler, H.: Mixing by Langmuir circulation in shallow lagoons, Baltica, ISSN 0067-3064, 23, 13-24, 2010.

Dähnke, K. and Thamdrup, B.: Nitrogen isotope dynamics and fractionation during sedimentary denitrification in Boknis Eck, Baltic Sea, Biogeosciences, 10, 3079-3088, doi:10.5194/bg-103079-2013, 2013.

Dale, A. W., Sommer, S., Bohlen, L., Treude, T., Bertics, V. J., Bange, H. W., Pfannkuche, O., Schorp, T., Mattsdotter, M. E.K., and Wallmann, K.: Rates and regulation of nitrogen cycling in seasonally hypoxic sediments during winter (Boknis Eck, SW Baltic Sea): Sensitivity to environmental variables, Estuar. Coast. Shelf S., 95, 14-28, 2011.

Fennel, W., Radtke, H., Schmidt, M., and Neumann, T.: Transient upwelling in the central Baltic Sea, Cont. Shelf Res., 30, 20152026, 2010.

Garau, B., Ruiz, S., Zhang, W. G., Pascual, A., Heslop, E., Kerfoot, J., and Tintoré, J.: Thermal lag correction on Slocum CTD glider data, J. Atmos. Ocean. Tech., 28, 1065-1071, 2011.

Gill, A. and Clarke, A.: Wind-induced upwelling, coastal currents and sea-level changes, Deep-Sea Res., 21, 325-345, 1974.

Gustafsson, E. and Omstedt, A.: Sensitivity of Baltic Sea deep water salinity and oxygen concentration to variations in physical forcing, Boreal Environ. Res., 14, 18-30, 2009.
Haapala, J.: Upwelling and its Influence on Nutrient Concentration in the Coastal Area of the Hanko Peninsula, Entrance of the Gulf of Finland, Estuar. Coast. Shelf S., 38, 507-521, 1994.

HELCOM (Ed.): Maritime Activities in the Baltic Sea, 123, 68 pp., Baltic Sea Environment Proceedings, 2010.

Hoppe, H.-G., Giesenhagen, H. C., Koppe, R., Hansen, H.-P., and Gocke, K.: Impact of change in climate and policy from 1988 to 2007 on environmental and microbial variables at the time series station Boknis Eck, Baltic Sea, Biogeosciences, 10, 4529-4546, doi:10.5194/bg-10-4529-2013, 2013.

Jakobsen, F., Hansen, I. S., Hansen, N.-E. O., and OstrupRasmussen, F.: Flow resistance in the Great Belt, the biggest strait between the North Sea and the Baltic Sea, Estuar. Coast. Shelf S., 87, 325-332, 2010.

Large, W. G. and Pond, S.: Open Ocean Momentum Flux Measurements in Moderate to Strong Winds, J. Phys. Oceanogr., 11, 324336, 1981.

Lass, H.-U., Mohrholz, V., Nausch, G., and Siegel, H.: On phosphate pumping into the surface layer of the eastern Gotland Basin by upwelling, J. Mar. Syst., 80, 71-89, 2010.

Lehmann, A. and Myrberg, K.: Upwelling in the Baltic Sea - A review, J. Mar. Syst., 74, Supplement, S3-S12, ISSN 0924-7963, doi:10.1016/j.jmarsys.2008.02.010, 2008

Lehmann, A., Myrberg, K., and Höflich, K.: A statistical approach to coastal upwelling in the Baltic Sea based on the analysis of satellite data for 1990-2009, Oceanologia, 54, 369-393, 2012.

Lennartz, S. T., Lehmann, A., Herrford, J., Malien, F., Hansen, H.P., Biester, H., and Bange, H. W.: Long-term trends at the Time Series Station Boknis Eck (Baltic Sea), 1957-2013: does climate change counteract the decline in eutrophication?, Biogeosciences Discuss., 11, 7615-7658, doi:10.5194/bgd-11-7615-2014, 2014.

Leppäranta, M. and Myrberg, K.: Physical oceanography of the Baltic Sea, 378, Springer/Praxis Publ., Berlin, Heidelberg, 2009.

Liblik, T. and Lips, U.: Variability of synoptic-scale quasistationary thermohaline stratification patterns in the Gulf of Finland in summer 2009, Ocean Sci., 8, 603-614, doi:10.5194/os-8603-2012, 2012.

Lips, I., Lips, U., and Liblik, T.: Consequences of coastal upwelling events on physical and chemical patterns in the central Gulf of Finland (Baltic Sea), Cont. Shelf Res., 29, 1836-1847, 2009.

McClain, C. R., Feldman, G. C., and Hooker, S. B.: An overview of the SeaWiFS project and strategies for producing a climate research quality global ocean bio-optical time series, Deep-Sea Res. Pt. II, 51, 5-42, 2004.

Merckelbach, L.: On the probability of underwater glider loss due to collision with a ship, J. Mar. Sci. Technol., 18, 75-86, 2013.

Myrberg, K. and Andrejev, O.: Main upwelling regions in the Baltic Sea - a statistical analysis based on three-dimensional modelling, Boreal Environ. Res., 8, 97-112, 2003.

Myrberg, K., Andrejev, O., and Lehmann, A.: Dynamic features of successive upwelling events in the Baltic Sea - a numerical case study, Oceanologia, 52, 77-99, 2010.

Ramp, S. R., Davis, R. E., Leonard, N. E., Shulman, I., Chao, Y., Robinson, A. R., Marsden, J., Lermusiaux, P. F. J., Fratantoni, D. M., Paduan, J. D., Chavez, F. P., Bahr, F. L., Liang, S., Leslie, W., and Li, Z.: Preparing to predict: The Second Autonomous Ocean Sampling Network (AOSN-II) experiment in the Monterey Bay, Deep-Sea Res. Pt. II, 56, 68-86, 2009. 
Reissmann, J., Burchard, H., Feistel, R., Hagen, E., Lass, H. U., Mohrholz, V., Nausch, G., Umlauf, L., and Wieczorek, G.: Vertical mixing in the Baltic Sea and consequences for eutrophication - A review, Progr. Oceanogr., 82, 47-80, 2009.

Ruiz, S., Pascual, A., Garau, B., Pujol, I., and Tintoré, J.: Vertical motion in the upper ocean from glider and altimetry data, Geophys. Res. Lett., 36, L14607, doi:10.1029/2009GL038569, 2009.

Saderne, V., Fietzek, P., and Herman, P. M. J.: Extreme Variations of $p \mathrm{CO}_{2}$ and $\mathrm{pH}$ in a Macrophyte Meadow of the Baltic Sea in Summer: Evidence of the Effect of Photosynthesis and Local Upwelling, PLoS ONE, 8, e62689, doi:10.1371/journal.pone.0062689, 2013.
Schweiger, B., Hansen, H. P., and Bange, H. W.: A time series of hydroxylamine $\left(\mathrm{NH}_{2} \mathrm{OH}\right)$ in the southwestern Baltic Sea, Geophys. Res. Lett., 34, L24608, doi:10.1029/2007GL031086, 2007.

Siegel, H., Gerth, M., and Tschersich, G.: Sea surface temperature development of the Baltic Sea in the period 1990-2004, Oceanologia, 48, 119-131, 2006.

Simpson, J., Brown, J., Matthews, J., and Allen, G.: Tidal straining, density currents, and stirring in the control of estuarine stratification, Estuaries, 13, 125-132, 1990.

Walin, G.: Some observations of temperature fluctuations in the coastal region of the Baltic, Tellus, 24, 187-198, 1972.

Yoshida, K.: Coastal upwelling off the California coast, Rec. oceanogr. Wks Japan, 2, 8-20, 1955. 